\title{
Low-grade inflammation in the rectum of patients with sporadic irritable bowel syndrome
}

\author{
MAGDY EL-SALHY $^{1,2}$, DORIS GUNDERSEN ${ }^{3}$, JAN GUNNAR HATLEBAKK ${ }^{2}$ and TRYGVE HAUSKEN ${ }^{2}$ \\ ${ }^{1}$ Department of Medicine, Section for Gastroenterology, Stord Helse-Fonna Hospital, Stord; \\ ${ }^{2}$ Section for Gastroenterology, Institute of Medicine, University of Bergen, Bergen; \\ ${ }^{3}$ Department of Research, Helse-Fonna, Haugesund, Norway
}

Received October 1, 2012; Accepted January 10, 2013

DOI: $10.3892 / \mathrm{mmr} .2013 .1320$

\begin{abstract}
Irritable bowel syndrome (IBS) is a common chronic gastrointestinal disorder that considerably reduces quality of life and is an economic burden on society. The pathogenesis of IBS is unknown. However, intestinal low-grade inflammation has been proposed as one of the factors contributing to the development of IBS. The present study aimed to examine the possible occurrence of low-grade inflammation in the rectum of patients with sporadic IBS. In total, 50 patients ( 42 females and 8 males with an average age of 34 years) with sporadic IBS fulfilling the Rome III Criteria were recruited for this study. Of these, 30 patients had IBS with diarrhoea as the predominant symptom (IBS-D) and 20 patients had IBS with constipation as the predominant symptom (IBS-C). A total of 27 control subjects (19 females and 8 males with an average age of 53 years) were included. The patients and controls underwent colonoscopy with rectal biopsies. The biopsies were immunostained for total leucocytes, lymphocytes, monocytes, macrophages and mast cells. The mucosal density of these cells was quantified by computer image analysis. The number of intraepithelial leucocytes and the density of the leucocytes in the lamina propria of the IBS patients did not differ from that of the controls. Similarly, there was no difference in the cell density of the mast cells in the lamina propria between the patients and the controls. The numbers of mucosal lymphocytes, macrophages and monocytes were low in the patients and the controls. These findings oppose low-grade inflammation as a pathogenic factor in sporadic IBS. Low-grade inflammation may, however, play an important role in the pathogenesis of a subset of IBS, namely post-infectious IBS (PI-IBS).
\end{abstract}

Correspondence to: Professor Magdy El-Salhy, Department of Medicine, Section for Gastroenterology, Stord Helse-Fonna Hospital, Box 4000, 5409 Stord, Norway

E-mail: magdy.el-salhy@helse-fonna.no

Key words: irritable bowel syndrome, lymphocytes, leucocytes, low-grade inflammation, macrophages, rectum, mast cells, sporadic

\section{Introduction}

Irritable bowel syndrome (IBS) is a chronic gastrointestinal disorder characterized by abdominal discomfort or pain associated with altered bowel habits, bloating and abdominal distension. In total, $5-20 \%$ of the world population has been reported to suffer from IBS (1). The degree and frequency of symptoms vary between patients, ranging from tolerable to severe and from daily symptoms to intermittent symptoms at intervals of weeks/months (2-14).

IBS is not known to be associated with the development of serious disease or with high mortality $(15,16)$. However, IBS considerably reduces quality of life to the same degree of impairment as major chronic diseases, including diabetes, congestive heart failure, renal insufficiency and hepatic cirrhosis (17-21). Besides the increased morbidity caused by IBS, the syndrome is an economic burden to society in varying forms, for example by increasing the incidence of sick leave and the over-consumption of healthcare resources (1).

The pathogenesis of IBS is unknown. Intestinal low-grade inflammation has been proposed as one of the factors contributing to the development of IBS (1). Support of this assumption is observed in histopathological examinations of mucosal biopsies from the ileum, caecum, colon and rectum, mostly from IBS patients with diarrhoea as the predominant symptom (IBS-D) but even from patients with constipation as the predominant symptom (IBS-C), which revealed a mucosal infiltration of mast cells and lymphocytes (22-28). Low-grade mucosal inflammation appears to be evident in a subset of IBS, i.e., post-infectious IBS (PI-IBS) $(1,24,26)$, but it is not clear, however, whether low-grade inflammation also occurs in sporadic IBS. The present study was therefore undertaken to examine the possible occurrence of low-grade mucosal inflammation in the rectum as a representative of the large intestine of patients with sporadic IBS.

\section{Patients and methods}

Patients and controls. In total, 50 patients with IBS that fulfilled the Rome III Criteria (http://www.romecriteria.org) using the IBS module were included in the study (29). These patients consisted of 42 females and 8 males with an average age of 34 years (range 18-62 years). Of these, 30 patients 
had IBS-D and 20 patients had IBS-C. All patients had their symptoms for numerous years and were not able to connect the onset of the IBS symptoms to any particular events, including gastrointestinal or other infections. All patients underwent a complete physical examination and had the following investigative blood tests: full blood count, electrolytes, calcium, inflammatory markers, liver and thyroid function tests. They underwent a gastroscopy with duodenal biopsies and coeliac disease was excluded.

The controls used in this study consisted of 27 subjects, 19 of which were female and 8 of which were male, with an average age of 53 years (range 20-65 years) that underwent colonoscopy with rectal biopsies. Of these subjects, 20 underwent colonoscopy due to gastrointestinal bleeding, where the source of the bleeding was identified as haemorrhoids (18) or angiodysplasia (2) and 7 subjects were examined due to health worries caused by a diagnosis of colon carcinoma in a relative. All control subjects had no other gastrointestinal complaints or systemic diseases.

The present study was performed in accordance with the Declaration of Helsinki and was approved by the local Committee for Medical Research Ethics. All subjects provided oral and written consent.

Colonoscopy. A standard colonoscopy was performed in the patients and controls, and biopsies were taken from the rectum $\sim 15 \mathrm{~cm}$ from the anus. The biopsies were fixed in $4 \%$ buffered paraformaldehyde overnight, embedded in paraffin and cut into $5-\mu \mathrm{m}$-thick sections.

Histopathology and immunohistochemistry. The sections were stained with haematoxylin and eosin and then immunostained with the avidin-biotin complex (ABC) method using the Vectastain ABC and the 3,3'-diaminobenzidine (DAB) Peroxidase Substrate kits (Vector Laboratories, Burlingame, CA, USA). The primary antibodies used were monoclonal mouse anti-human CD45 (Dako, Carpinteria, CA, USA; code no. M0701), monoclonal mouse anti-human CD47 (Dako; code no. I5647), monoclonal mouse anti-human CD68 (Dako; code no. M0814) and monoclonal mouse anti-human mast cell tryptase (Dako; code no. M7052). CD45 is considered as a leucocyte common antigen and is expressed exclusively on cells of the haematopoietic system and their progenitors. CD57 is expressed by subsets of NK cells and $\mathrm{CD} 8^{+}$lymphocytes and by a small percentage of $\mathrm{CD} 4^{+} / \mathrm{CD} 45 \mathrm{R} 0^{+} \mathrm{T}$ lymphocytes. CD68 labels human monocytes, macrophages and myeloid cells. Human mast cell tryptases comprise a family of trypsin-like neutral serine proteases that are predominantly expressed in mast cells.

Computerized image analysis. A computerised image analysis was performed using Olympus software: Cell D. When using $\mathrm{x} 40$ objectives, the frame (field) on the monitor represented an area of $0.14 \mathrm{~mm}^{2}$ of the tissue. The number of intraepithelial leucocytes cells and the area of the epithelial cells were measured in each field. The number of leucocytes, lymphocytes, macrophages and mast cells in the lamina propria were counted per microscopic field. All measurements were performed in 10 randomly chosen fields for each individual. The immunostained sections from the IBS patients and the

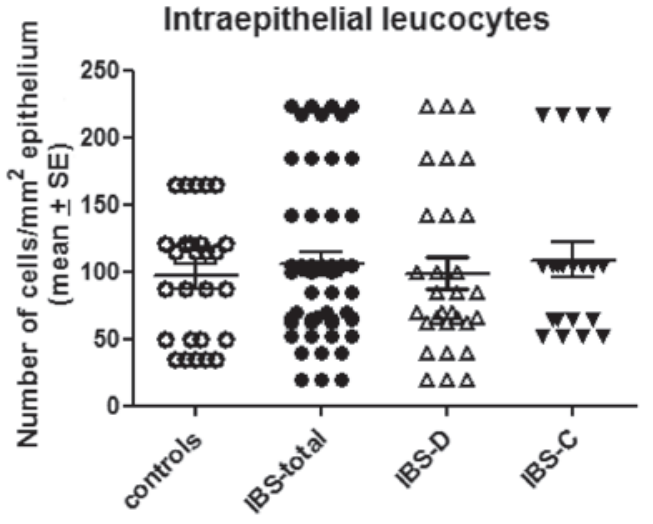

Figure 1. Number of intraepithelial leucocytes in the controls, IBS patients and IBS subtypes. IBS, irritable bowel syndrome; IBS-D, IBS with diarrhoea as the predominant symptom; IBS-C, IBS with constipation as the predominant symptom; SE, standard error.

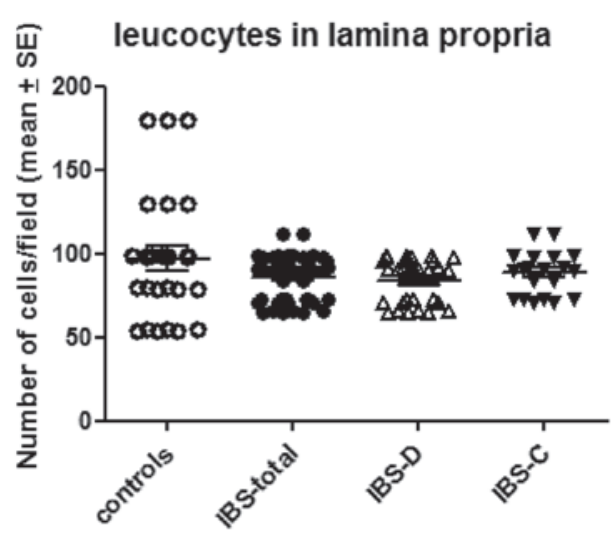

Figure 2. Number of leucocytes, as demonstrated by CD45, in the lamina propria of the controls, IBS patients and IBS subtypes. IBS, irritable bowel syndrome; IBS-D, IBS with diarrhoea as the predominant symptom; IBS-C, IBS with constipation as the predominant symptom; SE, standard error.

controls were coded and mixed and the measurements were taken without the knowledge of the section's identity.

Statistical analysis. A Mann-Whitney U test was performed and $\mathrm{P}<0.05$ was considered to indicate a statistically significant result.

\section{Results}

Colonoscopy, histopathology and immunohistochemistry. The colon and rectum of the patients and control subjects were macroscopically normal. Histopathological examination of the colon and rectum biopsies from the patients and controls revealed a normal histology.

\section{Computerised image analysis}

Leucocytes. The number of intraepithelial leucocytes observed in the controls, total IBS patients and the IBS-D and IBS-C patients was $95.2 \pm 48.4,102.1 \pm 16.2,98.8 \pm 20.6$ and $108 \pm 29 / \mathrm{mm}^{2}$ epithelium (mean \pm SE), respectively (Figs. 1 and 2). There was no statistically significant difference between the controls and the total IBS, IBS-D or IBS-C patients $(\mathrm{P}=0.97,0.96$ and 0.77 , respectively). 


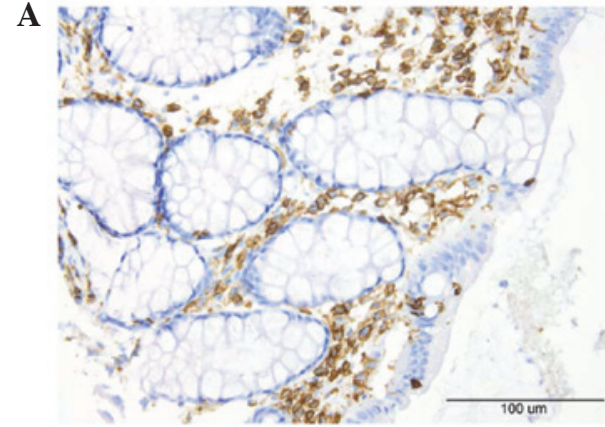

$\mathbf{B}$

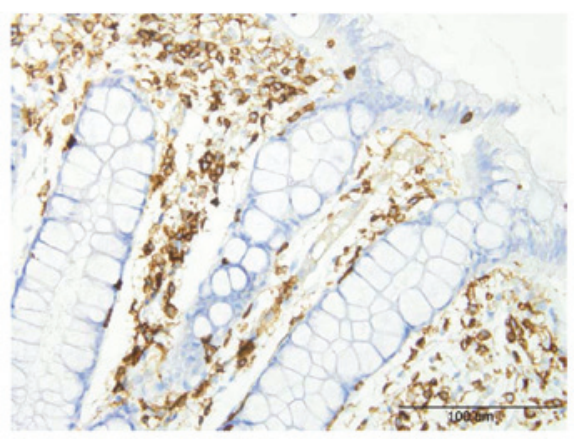

Figure 3. Leucocytes, as immunostained by CD45, in the epithelium and lamina propria of (A) a control subject and (B) an IBS patient. IBS, irritable bowel syndrome.

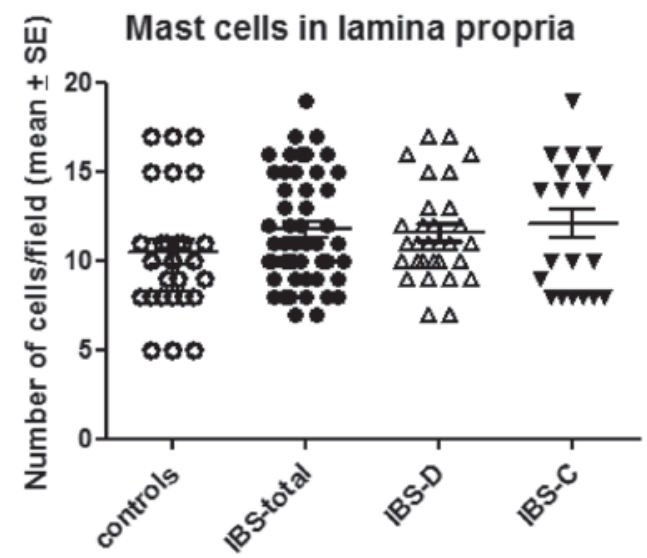

Figure 4. Density of the mast cells in the controls, IBS patients and the IBS-D and IBS-C subtypes. IBS, irritable bowel syndrome; IBS-D, IBS with diarrhoea as the predominant symptom; IBS-C, IBS with constipation as the predominant symptom; SE, standard error.

The number of leucocytes in the lamina propria was $97.1 \pm 7.2 /$ field in the controls and $85.8 \pm 1.9 /$ field in the total IBS patients. The corresponding figures in the IBS-D and IBS-C patients were $84.1 \pm 2.4$ and $88.3 \pm 2.9 /$ field, respectively (Figs. 2 and 3). There was no significant difference between the controls and the total IBS, IBS-D or IBS-C patients $(\mathrm{P}=0.17$, 0.13 and 0.48 , respectively).

Mast cells. The number of mast cells in the lamina propria of the controls, total IBS patients and the IBS-D and IBS-C patients was $10.4 \pm 0.7,11.7 \pm 0.4,11.5 \pm 0.5$ and $12.1 \pm 0.8 /$ field, respectively (Figs. 4 and 5). There was no sigificant difference between the controls and the total IBS patients $(\mathrm{P}=0.11)$. Nor was any significant difference observed between the controls and the IBS-D or IBS-C patients $(\mathrm{P}=0.01$ and 0.32$)$.

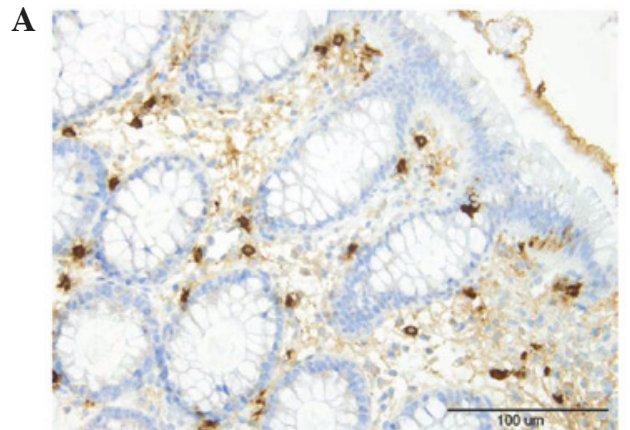

$\mathbf{B}$

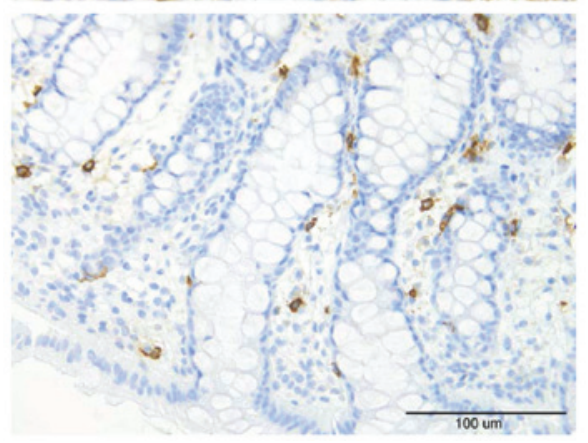

Figure 5. Mast cells in the lamina propria of (A) a control and (B) an IBS patient. IBS, irritable bowel syndrome.

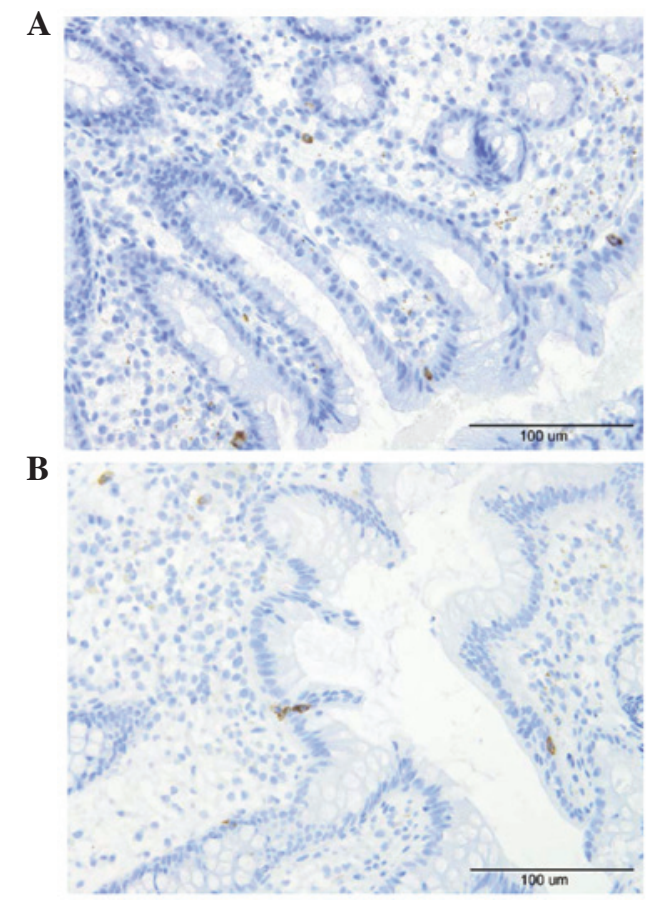

Figure 6. Lymphocytes are seldomly encountered in the epithelium and lamina propria in (A) the controls and (B) the patients with IBS. IBS, irritable bowel syndrome; IBS-D, IBS with diarrhoea as the predominant symptom; IBS-C, IBS with constipation as the predominant symptom.

Lymphocytes, macrophages and monocytes. A few lymphocytes were identified intraepithelially and in the lamina propria of the controls and the patients (Fig. 6). Macrophages and monocytes were seldomly encountered in the lamina propria of the controls or patients. These three cell types were sparse in the biopsy material examined which made it difficult to perform a reliable quantification. 


\section{Discussion}

In unselected cohorts of IBS patients, an increased mucosal cell density of mast cells was observed in the ileum, caecum and colon $(22,23,25,27)$, however, this increase did not occur in all IBS patients that were examined $(22,25,27)$. A previous study reported that numbers of plasma cells, lymphocytes, eosinophils, neutrophils and macrophages were unchanged in a cohort of unselected IBS patients (23). However, a second study of another cohort of unselected IBS patients identified an increase of lymphocytes in $50 \%$ of the patients (27). It is conceivable to conclude, therefore, that the increased infiltration of immune cells in the terminal ileum, colon and rectum occurs only in a subset of IBS patients.

PI-IBS is a subset of IBS that is defined as a sudden onset of IBS symptoms following gastroenteritis in individuals who previously have not had any gastrointestinal complaints (30). PI-IBS however, has also been reported following non-gastrointestinal infections, including respiratory, urinary tract and skin infections (31). Sporadic IBS, however, may be defined as a long duration of IBS symptoms in individuals without any connection to a previous gastrointestinal infection. In total, $6-17 \%$ of patients with IBS believe that their symptoms began with an infective illness (32). Furthermore, $7-31 \%$ of patients who suffer an acute episode of infectious gastroenteritis develop PI-IBS despite clearance of the inciting pathogen (33).

The intestinal mucosa of patients with PI-IBS, as well as of the animal models for PI-IBS, show a low-grade inflammation. Thus, in patients with chronic giardiasis (patients with Giardia infection despite antibiotic treatment), as well as in patients with PI-IBS following Giardia infection, an increased intraepithelial infiltration of lymphocytes has been observed in the duodenal mucosa. The lymphocyte infiltration in chronic giardiasis was reported to be much more prominent than in PI-IBS (28). Similarly, an increased infiltration of $\mathrm{T}$ lymphocytes, as well as mast cells, has been reported in the duodenal and jejunal mucosa of an animal model for PI-IBS (34). In the terminal ileum of PI-IBS patients following Shigella infection, an increase in the number of mast cells was also observed (35). The density of $\mathrm{T}$ lymphocytes and mast cells was increased in the lamina propria of the rectum in patients with PI-IBS $(24,34,35)$. Similarly, rectal biopsies taken from patients following Campylobacter enteritis showed an increase in the density of CD3, CD4 and CD8 lymphocytes in the intraepithelium and in the lamina propria, which persisted for $>1$ year subsequent to infection $(26,36)$.

The present study showed that the mucosal density of leucocytes as a whole and lymphocytes, monocytes, macrophages and mast cells in the rectum in the sporadic IBS patients did not differ from that of the controls. These findings oppose low-grade inflammation as a pathogenic factor in sporadic IBS. From the data presented above, low-grade inflammation may play a role in the pathogenesis of a subset of IBS, namely PI-IBS.

\section{Acknowledgements}

This study was supported by a grant from Helse-Fonna.

\section{References}

1. El-Salhy M, Gundersen D, Hatlebakk JG and Hausken T (eds): Irritable Bowel Syndrome. Nova Scientific Publishers, New York, NY, 2012.

2. Agréus L, Svärsudd K, Nygrén O and Tibblin G: Irritable bowel syndrome and dyspepsia in the general population: overlap and lack of stability over time. Gastroenterology 109: 671-680, 1995.

3. Thompson WG and Heaton KW: Functional bowel disorders in apparently healthy people. Gastorenterology 79: 283-288, 1980.

4. Kennedy TM, Jones RH, Hungin AP, O'Flanagan H and Kelly P: Irritable bowel syndrome, gastro-oesophageal reflux, and bronchial hyper-responsiveness in the general population. Gut 43: 770-774, 1998

5. Drossman DA, Li Z, Andruzzi E, Temple RD, Talley NJ, Thompson WG, Whitehead WE, Janssens J, Funch-Jensen P, Corazziari E, et al: U.S. householder survey of functional gastrointestinal disorders. Prevalence, sociodemography, and health impact. Dig Dis Sci 38: 1569-1580, 1993.

6. Talley NJ, Gabriel SE, Harmsen WS, Zinsmeister AR and Evans RW: Medical costs in community subjects with irritable bowel syndrome. Gastroenterology 109: 1736-1741, 1995.

7. Hungin AP, Whorwell PJ, Tack J and Mearin F: The prevalence, patterns and impact of irritable bowel syndrome: an international survey of 40,000 subjects. Aliment Pharmacol Ther 17: 643-650, 2003.

8. Jones R and Lydeard S: Irritable bowel syndrome in the general population. BMJ 304: 87-90, 1992.

9. Bordie AK: Functional disorders of the colon. J Indian Med Assoc 58: 451-456, 1972

10. O'Keefe EA, Talley NJ, Zinsmeister AR and Jacobsen SJ: Bowel disorders impair functional status and quality of life in the elderly: a population-based study. J Gerontol A Biol Sci Med Sci 50: M184-M189, 1995.

11. Everhart JE and Renault PF: Irritable bowel syndrome in office-based practice in the United States. Gastroenterology 100: 998-1005, 1991.

12. Wilson S, Roberts L, Roalfe A, Bridge P and Singh S: Prevalence of irritable bowel syndrome: a community survey. Br J Gen Pract 54: 495-502, 2004.

13. Harvey RF, Salih SY and Read AE: Organic and functional disorders in 2000 gastroenterology outpatients. Lancet 1: 632-634, 1983.

14. Spiegel BM: The burden of IBS: looking at metrics. Curr Gastroenterol Rep 11: 265-269, 2009.

15. Thompson WG: A world view of IBS. In: Irritable Bowel Syndrome: Diagnosis and Treatment. Camilleri M and Spiller R (eds). Saunders Ltd., Philadelphia and London, pp17-26, 2002.

16. Quigley EM, Locke GR, Mueller-Lissner S, Paulo LG, Tytgat GN, Helfrich I and Schaefer E: Prevalence and management of abdominal cramping and pain: a multinational survey. Aliment Pharmacol Ther 24: 411-419, 2006.

17. Miller V, Whitaker K, Morris JA and Whorwell PJ: Gender and irritable bowel syndrome: the male connection. J Clin Gastroenterol 38: 558-560, 2004.

18. Whitehead WE, Burnett CK, Cook EW III and Taub E: Impact of irritable bowel syndrome on quality of life. Dig Dis Sci 41: 2248-2253, 1996.

19. Gralnek IM, Hays RD, Kilbourne A, Naliboff B and Mayer EA: The impact of irritable bowel syndrome on health related quality of life. Gastroenterology 119: 654-660, 2000.

20. Huerta I, Hinojosa C, Santa Maria A and Schmulson M: Diferencias en la calidad de vida (CV) entre pacientes con sindrome de Intestino irritable (SII) y la poblacon mexicana evaluadas mediante el SF-36. Rev Mex Gastroenterol 66 (Suppl 2): 145-146, 2001 (In Spanish).

21. Schmulson M, Robles G, Kershenobich, Lopez-Ridaura R, Hinojosa C and Durate A: Los pacientes con trastornos funcionales digestivos (TFD) tienen major compromiso de la calidad de vida (CV) evaluadas por el SF-36 comparados con pacientes con hepatitis C y pancreatitis cronica. Rev Mex Gastroenterol 65 (Suppl-Resumenes): 50-51, 2000 (In Spanish).

22. Weston AP, Biddle WL, Bhatia PS and Miner PB Jr: Terminal ileal mucosal mast cells in irritable bowel syndrome. Dig Dis Sci 38: $1590-1595,1993$.

23. O'Sullivan M, Clayton N, Breslin NP, Herman I, Bountra C, McLaren A and O'Morain CA: Increased mast cells in the irritable bowel syndrome. Neurogastroenterol Motil 12: 449-457, 2000 . 
24. Dunlop SP,Jenkins D, Neal KR and Spiller RC: Relative importance of enterochromaffin cell hyperplasia, anxiety and depression in post-infectious IBS. Gastroenterology 125: 1651-1659, 2003

25. Barbara G, Stanghellini V, De Giorgio R, Cremon C, Cottrell GS, Santini D, Pasquinelli G, Morselli-Labate AM, Grady EF, Bunnett NW, Collins SM and Corinaldesi R: Activated mast cells in proximity to colonic nerves correlate with abdominal pain in irritable bowel syndrome. Gastroenterology 126: 693-702, 2004.

26. Spiller RC, Jenkins D, Thornley JP, Hebden JM, Wright T, Skinner M and Neal KR: Increased rectal mucosal enteroendocrine cells, T lymphocytes, and increased gut permeability following acute Campylobacter enteritis and in post-dysenteric irritable bowel syndrome. Gut 47: 804-811, 2000.

27. Cremon C, Gargano L, Morselli-Labate AM, Santini D, Cogliandro RF, De Giorgio R, Stanghellini V, Corinaldesi R and Barbara G: Mucosal immune activation in irritable bowel syndrome: gender-dependence and association with digestive symptoms. Am J Gastroenterol 104: 392-400, 2009.

28. Dizdar V, Hanevik K, Lærum OD, Gilja OH, Langeland N and Hausken T: Duodenal mucosal lymphocytes in Giardia-induced functional gastrointestinal disorder. Presented at the 19th United European Gastroenterology Week (UEGW) (abstract P0996), 2011.

29. Longstreth GF, Thompson WG, Chey WD, Houghton LA, Mearin F and Spiller RC: Functional bowel disorders. Gastroenterology 130: 1480-1491, 2006.
30. Ghoshal UC, Park H and Gwee KA: Bugs and irritable bowel syndrome: The good, the bad and the ugly. J Gastroenterol Hepatol 25: 244-251, 2010.

31. Mckeown ES, Parry D, Stansfield R, Barton JR and Welfare MR: Postinfectious irritable bowel syndrome may occur after non-gastrointestinal and intestinal infection. Neurogastroenterol Motil 18: 839-843, 2006.

32. Longstreth CF, Hawkey CJ, Mayer EA, Jones RH, Naesdal J, Wilson IK, Peacock RA and Wiklund IK: Characteristics of patients with irritable bowel syndrome recruited from three sources: implications for clinical trials. Aliment Pharmacol Ther 15: 959-964, 2001.

33. Spiller R and Garsed K: Infection, inflammation and the irritable bowel syndrome. Dig Liver Dis 41: 844-849, 2009.

34. Wheatcroft J, Wakelin D, Smith A, Mahoney CR, Mawe G and Spiller R: Enterochromaffin cell hyperplasia and decreased serotonin transporter in a mouse model of postinfectious bowel dysfunction. Neurogastroenterol Motil 17: 863-870, 2005.

35. Wang LH, Fang XC and Pan GZ: Bacillary dysentery as a causative factor for irritable bowel syndrome and its pathogenesis. Gut 53: 1096-1101, 2004.

36. Lee KJ, Kim YB, Kim JH, Kwon HC, Kim DK and Cho SW: The alteration of enterochromaffin cell, mast cell, and lamina propria $\mathrm{T}$ lymphocyte numbers in irritable bowel syndrome and its relationship with psychological factors. J Gastroenterol Hepatol 23: 1689-1694, 2008 . 